\title{
DA ELABORAÇÃO DE PROJETOS À CONSTRUÇÃO DE CONCEITOS ESTATÍSTICOS: UMA EXPERIÊNCIA COM ALUNOS DO ENSINO MÉDIO
}

\author{
FROM ELABORATION OF PROJECTS TO THE CONSTRUCTION OF \\ STATISTICAL CONCEPTS: AN EXPERIENCE WITH HIGH SCHOOL STUDENTS \\ DE LA ELABORACIÓN DE PROYECTOS A LA CONSTRUCCIÓN DE \\ CONCEPTOS ESTADÍSTICOS: UNA EXPERIENCIA CON ESTUDIANTES DE \\ ESCUELA SECUNDARIA
}

Jadson de Souza Conceição ${ }^{1}$

\begin{abstract}
RESUMO
O presente artigo relata uma experiência de ensino desenvolvida ao longo das aulas de Estatística, no $2^{\circ}$ trimestre do ano letivo de 2019, em uma Escola Estadual localizada na região da Chapada Diamantina, na Bahia, e objetivou desenvolver nos estudantes do Ensino Médio, por meio da metodologia de elaboração de projetos de pesquisa, o letramento estatístico. Para tanto, foi realizado um estudo de natureza qualitativa, guiado pelo Modelo SKOPOS, em três pilares: (i) escopo; (ii) plano de ação e (iii) plano de controle e avaliação. Os dados coletados foram analisados sob dois tópicos: os projetos de pesquisa e seus resultados e as reflexões sobre os projetos de pesquisa. Ao final desta experiência, foi possível perceber que a proposta de atividades favoreceu a aprendizagem dos estudantes no tocante à Estatística. Esses resultados induzem à conclusão de que a realização da atividade, por meio da elaboração de projetos, proporcionou aos alunos o desenvolvimento do letramento estatístico, como também os conscientizou sobre os papéis que eles desempenham na sociedade, principalmente no que diz respeito ao exercício da cidadania e criticidade.
\end{abstract}

Palavras-chave: Estatística. Projetos de Pesquisa. Letramento estatístico. Ensino Médio. Criticidade

\begin{abstract}
This article reports on a teaching experience developed over the course of Statistics classes, in the II quarters of the academic year 2019, at a State School, located in the Chapada Diamantina region, in Bahia e and it aimed to develop statistical literacy in high school students, through the methodology of elaborating research projects. To this end, a qualitative study was carried out, guided by the SKOPOS Model, on three pillars: (i) scope; (ii) action plan and (iii) control and evaluation plan. The collected data were analyzed under two topics: (a) research projects and their results and (b) reflections on research projects. At the end of this experience, it was possible to notice that the proposed activities favored the students' learning regarding Statistics. These results lead us to conclude that the performance of the activity, through the elaboration of projects, provided students with the development of statistical literacy, as well as made them aware of the roles they play in society, especially with regard to the exercise of citizenship and criticality.
\end{abstract}

Keywords: Statistics. Research Project. Statistical Literacy. High School. Criticality.

${ }^{1}$ Mestre em Educação Matemática pela Universidade Estadual de Santa Cruz (UESC). Professor da Rede
Estadual de Educação da Bahia - Colégio Estadual Professora Nilde Maria Monteiro Xavier (SEC-
BA/CEPNMMX), Palmeiras, Bahia, Brasil. Endereço para correspondência: Rua Carlos Torres, 96, Centro,
Palmeiras, Bahia, Brasil, CEP: 46930-000. E-mail: jadson.conceicao@enova.educacao.ba.gov.br. 


\section{RESUMEN}

El presente artículo informa una experiencia docente desarrollada durante las clases de Estadística, en el segundo trimestre del año académico de 2019, en una Escuela Pública ubicada en la región de la Chapada Diamantina, en Bahia, y tuvo como objetivo desarrollar la alfabetización estadística en estudiantes de escuela secundaria, a través de la metodología de elaboración de proyectos de investigación. Para ello, se realizó un estudio cualitativo, guiado por el Modelo SKOPOS, en tres pilares: (i) alcance; (ii) plan de acción y (iii) plan de control y evaluación. Los datos recopilados fueron analizados en dos temas: proyectos de investigación y sus resultados y reflexiones sobre proyectos de investigación. Al final de esta experiencia, se pudo observar que las actividades propuestas favorecieron el aprendizaje de los estudiantes en Estadística. Estos resultados llevan a la conclusión que el desempeño de la actividad, mediante elaboración de proyectos, proporcionó a los estudiantes el desarrollo de la alfabetización estadística, pero también los sensibilizó de los roles que desempeñan en la sociedad, principalmente en respecto al ejercicio de la ciudadanía y la criticidad.

Palabras clave: Estadística. Proyecto de Investigación. Alfabetización. Escuela Secundaria. Criticidad.

\section{INTRODUÇÃO}

"Matemática é algo muito complicado!”. Esta é uma fala comum entre os alunos da Educação Básica quando estes se deparam com alguma situação matemática que não conseguem resolver, principalmente dita por aqueles que apresentam dificuldades em estabelecer conexões entre os conceitos estudados e o seu meio. De acordo com Burak (1994), essas dificuldades, presentes no processo de aprendizagem da Matemática, têm relação com a preocupação do professor em cumprir o planejamento, em alguns casos, em detrimento da aprendizagem dos alunos. Outra perspectiva é a de que com os avanços tecnológicos, os interesses dos alunos mudaram, mas a Escola e a sua organização se mantiveram estáticas.

Assim, em vários espaços educacionais não tem sido oferecida aos alunos uma formação que lhes permita estabelecer conexões com as suas realidades ou outras áreas de conhecimento, atreladas, sobretudo, a um modelo de ensino tradicional que vem sufocando a capacidade desses discentes, desmotivando-os e os tornando meros reprodutores de informações.

Esta realidade vai de encontro a uma das principais metas da educação, proposta por Piaget (1976, p. 246), que é “[...] criar homens que sejam capazes de fazer coisas novas, não simplesmente repetir o que outras gerações já fizeram. Homens que sejam criadores, inventores, descobridores”. Diante disso, faz-se necessário um novo olhar para o ensino de Matemática, em que a reprodução dá espaço para a descoberta, criação, investigação, criatividade e invenção. 
Diante do exposto, o presente estudo foi desenvolvido ao longo das aulas de Estatística, no $2^{\circ}$ trimestre do ano letivo de 2019, em uma Escola Estadual localizada na região da Chapada Diamantina, na Bahia, e objetivou desenvolver nos estudantes do Ensino Médio, por meio da metodologia de elaboração de projetos de pesquisa, o letramento estatístico. As ações da atividade ocorreram em uma turma do terceiro ano do Ensino Médio, composta por 37 alunos, com idade média de 17 anos. Nesta turma, abordaram-se os conceitos de população, amostra, variáveis, gráficos e tabelas, medidas de tendência central (média, moda e mediana), além da construção de gráficos e tabelas utilizando o Excel.

$\mathrm{Na}$ busca por subsídios que nos conduzissem a atingir o objetivo proposto, apresentase aqui uma breve descrição acerca da organização deste estudo. Na presente introdução é posta a motivação para a realização do trabalho, assim como a problemática e o objetivo que norteiam este estudo. Na seção 2 - referencial teórico, são delineados os principais elementos e características da Educação Estatística e, com mais afinco, as contribuições do trabalho com o projeto para o ensino de Estatística na Educação Básica.

Já na seção 3 - proposta de trabalho e percurso metodológico, são apresentados os pressupostos teórico-metodológicos que guiaram o desenvolvimento e a natureza da presente pesquisa. Quanto à 4 seção - reflexão acerca dos resultados, nela foram apresentados e analisados os dados coletados e produzidos, sob duas categorias de análise: (i) os projetos de pesquisa e seus resultados e (ii) as reflexões sobre os projetos de pesquisa. Finalmente, em Considerações Finais, explicitam-se a resposta referente ao objetivo de pesquisa, as contribuições do estudo para os estudantes e o fazer pedagógico dos professores.

\section{REFERENCIAL TEÓRICO}

Pensar o ensino de Matemática, nas perspectivas atuais e nas ideias propostas por Piaget (1976), é reconhecer que as dificuldades são mais acentuadas, uma vez que os resultados divulgados em 2016 pelo Ministério da Educação (MEC), e apontados pelo Programa Internacional de Avaliação de Estudantes (Pisa) - Programme for International Student Assessment - da Organização para a Cooperação e Desenvolvimento Econômico (OCDE), mostraram que o desempenho médio em Matemática, dos estudantes brasileiros de 15 anos, foi de 377 pontos (MEC, 2016). Esse desempenho foi inferior à média de 490 pontos, alcançada pelos estudantes dos demais países membros da OCDE. 
Essa realidade não é diferente quando se pensa no estado da Bahia. Dados do Índice de Desenvolvimento da Educação Básica (IDEB) destacaram que a Bahia apresentou desempenho inferior ao da última edição, em 2015, ficando abaixo da média pretendida e ocupando a última colocação no ranking nacional. Além disso, os dados do Anuário Brasileiro da Educação Básica (2019), divulgados pelo movimento "Todos pela Educação", no mesmo ano, em parceria com a Editora Moderna, apontaram que apenas 4,7\% dos estudantes do Ensino Médio, do território baiano, têm proficiência adequada em Matemática.

Esses resultados são reflexos da formação promovida pela maioria das escolas, que têm formado alunos com pouca criatividade, criticidade, proatividade, que não desempenham papéis de atores principais no seu aprendizado e que não se apropriam do conhecimento como fator necessário ao seu desenvolvimento integral (BRASIL, 2018). Assim, faz-se necessário que a escola proponha um ensino em que a Matemática seja desenvolvida de forma contextualizada, integrada e relacionada a outros conhecimentos, de modo que traga em si o desenvolvimento de competências e habilidades que são essencialmente formadoras do ponto de vista da Matemática e da Educação (BRASIL, 2002, 2018).

Dentre as áreas de estudos que compõem o Currículo da Educação Básica, é possível destacar o tratamento da informação, o qual possibilita, a depender da condução e abordagem do professor, um processo de aprendizagem mais humano e próximo da realidade do aluno, visto que a Estatística tem desempenhado na sociedade, nos últimos anos, papel fundamental para explicar e analisar diversas situações, a exemplo da tomada de decisões (CONCEIÇÃO et al., 2019). De acordo com Cazorla et al. (2017), o trabalho com a Estatística no Ensino Básico desenvolve no aluno a formação crítica frente às questões de cunho social, político, cultural e científico.

$\mathrm{Na}$ mesma direção, Gal (2002, p. 2, tradução nossa) pontua que esse trabalho também desenvolve o letramento estatístico ${ }^{2}$, o qual a autora se refere como a:

(a) habilidade da pessoa de interpretar e avaliar criticamente informações estatísticas, argumentos relacionados a dados ou fenômenos estocásticos, que eles podem encontrar em contextos diversos, e quando relevante, (b) as habilidades deles de discutir ou comunicar suas reações a essas informações estatísticas, como seu entendimento do significado das informações, suas opiniões sobre as implicações

\footnotetext{
${ }^{2}$ The term "statistical literacy" refers broadly to two interrelated components, primarily (a) people's ability to interpret and critically evaluate statistical information, data-related arguments, or stochastic phenomena, which they may encounter in diverse contexts, and when Adults' Statistical Literacy 3 relevant (b) their ability to discuss or communicate their reactions to such statistical information, such as their understanding of the meaning of the information, their opinions about the implications of this information, or their concerns regarding the acceptability of given conclusions. 
dessas informações ou suas preocupações quanto à aceitabilidade de conclusões dadas (GAL, 2002, p. 2, tradução nossa).

A autora pontua que ambos os componentes atuam simultaneamente, isto é, de forma interrelacionada. Além disso, aborda que o letramento estatístico está relacionado à capacidade que o aluno tem de interpretar e avaliar criticamente as informações estatísticas, sendo estas condições necessárias para se alcançar essa forma de letramento (GAL, 2002).

Desse modo, faz-se necessário que a escola desenvolva um trabalho em que a leitura, discussão e análise de questões referentes à ciência e tecnologia; diversidade cultural; educação alimentar e nutricional; educação ambiental; educação para a valorização do multiculturalismo nas matrizes históricas e culturais brasileiras; educação em direitos humanos; educação financeira; educação para o trânsito; saúde, trabalho, vida familiar e social, bem como temas contemporâneos transversais, propostos pela Base Nacional Comum Curricular (BNCC), que quase sempre estão entrelaçadas com índices, tabelas e gráficos, façam-se presentes nas aulas de Matemática, de modo que os alunos consigam desenvolver o letramento estatístico (GAL, 2002).

Os Parâmetros Curriculares Nacionais para o Ensino Médio ( $\mathrm{PCN}+$ ) destacam que durante o Ensino Médio é impreterível a discussão de temáticas como as abordadas anteriormente, mas é preciso que os estudantes ultrapassem a leitura de informações e passem a refletir sobre os seus significados (BRASIL, 2002). Na mesma direção, Lopes (2008) aponta que essas discussões, além de desenvolverem a reflexão e criticidade, auxiliam os alunos no exercício de sua cidadania. A autora define o exercício da cidadania como a "capacidade de atuação reflexiva, ponderada e crítica de um indivíduo em seu grupo social [...]” (LOPES, 2008, p. 60).

Ainda com relação à necessidade de se desenvolver o letramento estatístico, a BNCC pontua que uma das habilidades que os estudantes do Ensino Médio devem desenvolver é:

Planejar e executar pesquisa amostral usando dados coletados ou de diferentes fontes sobre questões relevantes atuais, incluindo ou não, apoio de recursos tecnológicos, e comunicar os resultados por meio de relatório contendo gráficos e interpretação das medidas de tendência central e das de dispersão (BRASIL, 2018, p. 526).

Portanto, é imprescindível que no Ensino Médio os alunos tenham contato com situações reais, que permitam refletir acerca de contextos sociais e locais. Segundo Lopes (2008, p. 62), é de extrema necessidade que atividades em estatísticas façam referência às realidades vividas pelos estudantes, pois "construir gráficos e tabelas desvinculados de um 
contexto ou relacionados a situações muito distantes do aluno pode estimular a elaboração de um pensamento, mas não garante o desenvolvimento de sua criticidade". Assim, trabalhar a Estatística, seja por meio de sequência de ensino, perspectiva interdisciplinar e/ou elaboração de projetos, visa ao desenvolvimento da criticidade.

Com relação à elaboração de projetos, Moura e Barbosa (2017, p. 17) pontuam que: "são atividades realizadas por alunos sob orientação de professores, visando à construção do conhecimento, formação de habilidades e competências [...]. Este procedimento pedagógico é desenvolvido tendo por base uma metodologia conhecida por 'método de projetos' [...]". Na mesma direção, Masetto (2001, p. 98) afirma que a proposta de elaboração de projetos "é, sem dúvida, uma das mais completas e envolventes atividades pedagógicas coletivas".

Assim, trabalhar a Estatística, na perspectiva da elaboração de projetos, em que envolve amostra, levantamento de dados e análise de informações reais, não só desenvolve o letramento estatístico, como, também, o processo de interação e troca com seus pares, tendo em vista que os alunos adquirem experiências e constroem a noção de pertencimento, identidade e territorialidade, elementos importantes para a formação de cidadão críticos (CARVALHO, 2012).

Bianchini, Bisognin e Soares (2015, p. 10) destacam que nas atividades que têm como ponto de partida a pesquisa, os alunos se sentem motivados a participar e se envolvem mais, apresentando condições de realizar bons trabalhos. Ainda de acordo com os autores, o trabalho com as atividades de pesquisa "que envolvam coleta e análise de dados, onde seja possibilitada a participação ativa dos alunos na construção da proposta e lhes sejam possibilitados diferentes caminhos para sua efetivação, tornam as aulas de matemática instigantes e reflexivas" (p. 10).

Em síntese, atividades de pesquisa favorecem a interação entre os alunos e valorizam a diversidade de opiniões, sem distinção e/ou preconceito. De acordo com Lopes (2008, p. 70), "ao conduzir uma investigação estatística, os estudantes aprendem a interpretar resultados e a estar cientes sobre as tendências possíveis ou limitações nas generalizações que podem ser obtidas dos dados". Assim, trabalhar com a pesquisa como meio para o ensino de Estatística capacita os estudantes a questionarem a veracidade e generalizações das interpretações de dados, representações gráficas e de estudos realizados com uma pequena amostra.

Portanto, parece haver um consenso entre muitos autores de que o ensino de Estatística possibilita o desenvolvimento intelectual, cognitivo e moral dos alunos. Assim, o trabalho com dados relacionados às questões sociais reais e locais, em sala de aula, pode desenvolver a 
criticidade, a solidariedade e o respeito ao diferente na sua comunidade. Isto porque uma das áreas de atuação da Estatística são os estudos acerca de problemas sociais, tomada de decisão e de interesses da sociedade (política, futebol, etc.).

\section{PROPOSTA DE TRABALHO E PERCURSO METODOLÓGICO}

O presente estudo é de natureza qualitativa e teve o objetivo principal de desenvolver nos estudantes do Ensino Médio, por meio da metodologia de elaboração de projetos de pesquisa, o letramento estatístico. $\mathrm{O}$ estudo de viés qualitativo tem como característica a subjetividade, que ocorre em todas as suas etapas de realização (LÜDKE; ANDRÉ, 1986). A pesquisa em questão trata sobre essa subjetividade, pois versa sobre a interpretação estatística a respeito de questões sociais do contexto dos alunos.

Além disso, considerando-se as recomendações da BNCC e as reformulações do Novo Ensino Médio, cabe à escola desenvolver no aluno o comportamento pesquisador ${ }^{3}$. Nesta perspectiva, faz-se necessário que o ato de pesquisar também seja ensinado no ambiente escolar. Assim sendo, o presente estudo foi desenhado nos moldes da metodologia de projetos. De acordo com Freitas (2003, p. 21), a adoção dessa metodologia para o desenvolvimento de uma prática escolar deve convergir com os objetivos da própria metodologia de projetos, isto é:

Possibilitar a interação do aluno no processo de construção do conhecimento. Viabilizar a aprendizagem real, significativa, ativa e interessante. Trabalhar o conteúdo conceitual de forma procedimental e atitudinal. Proporcionar ao aluno uma visão globalizada da realidade e um desejo contínuo da aprendizagem.

Assim, a metodologia de projeto tem como pano de fundo a problematização do meio no qual o aluno está inserido. Portanto, é de responsabilidade do discente "investigar, registrar dados, formular hipóteses, tomar decisões, resolver o problema, tornando-se sujeito de seu próprio conhecimento" (OLIVEIRA, 2006, p. 13). Desta forma, uma pesquisa, na área de Matemática, que se baseia na metodologia de projetos, visa construir com os estudantes, a partir de análises, interpretações e por meio da resolução de problemas, conceitos matemáticos que se manifestam em diferentes contextos.

${ }^{3}$ Ensinar o "comportamento pesquisador" implica o desenvolvimento da própria intelectualidade, de um
exercício crítico-reflexivo que demanda uma aprendizagem ativa e, assim, exige daquele que pesquisa as
capacidades de analisar, comparar, refletir, levantar hipóteses, estabelecer relações, sintetizar, generalizar etc.
Disponível em: http://basenacionalcomum.mec.gov.br/implementacao/praticas/caderno-de-praticas/aprofunda
mentos/192-metodologia-de-pesquisa-na-escola. Acesso em: 15 maio 2020. 
Moura e Barbosa (2006) apontam que a metodologia de projetos é guiada por um escopo - Modelo SKOPOS - em três pilares: (i) escopo: descreve em linhas gerais o propósito e a realização, colocando-os em prática no projeto, bem como o tema, objetivo, problemática, resultados e extensão do trabalho; (ii) plano de ação: elenca e detalha os recursos que serão utilizados para alcançar o que foi proposto no escopo. Além disso, seu desenvolvimento, tempo, recursos, custos e planejamento; e (iii) plano de controle e avaliação: pontuam os processos de análise do desenvolvimento e avaliam os resultados obtidos no projeto.

É válido salientar que os autores apontam que esse modelo não é estático e pode sofrer adequações de acordo com o problema trabalhado. Procurando atender a esses pilares, explicitaremos, a seguir, como as ações do projeto foram desenvolvidas.

(i) Escopo: foi proposto tema livre, isto é, os alunos tiveram a liberdade de escolher quais problemas gostariam de investigar; a única exigência era que fosse retratada a realidade da cidade em que eles residem; neste caso, o município de Palmeiras. Diante disso, os alunos se organizaram em grupos com quatro componentes, por critérios de afinidades, e escolheram quais problemas gostariam de tratar. Os temas foram os mais variados: gravidez na adolescência, satisfação política, diabetes, turismo, taxa de analfabetismo, dengue, violência contra a mulher e alcoolismo.

(ii) Plano de ação: após a escolha das temáticas a serem investigadas, os alunos realizaram um estudo a respeito delas. Buscaram por notícias, livros, textos e outros materiais que abordassem o assunto selecionado. Após o estudo do tema, solicitou-se aos alunos a elaboração de um questionário para a produção e coleta dos dados, o qual seria aplicado ao público-alvo de suas pesquisas;

(iii) Plano de controle e avaliação: nesta etapa, de posse dos questionários respondidos, os alunos, com a mediação do professor, passaram para a etapa da análise, buscando estabelecer conexões entre conceitos matemáticos e os dados produzidos e coletados por eles. Após longas discussões e reflexões acerca desses dados, buscou-se filtrar todas as informações relevantes, criando conexões com a Estatística. Os resultados da etapa (ii) e as reflexões desenvolvidas foram, inicialmente, transcritos no relatório de pesquisa e socializados com os demais alunos da turma, no formato de seminário. Passados pelo crivo da turma, esses seminários foram ampliados e 
apresentados, em formato de palestra, à comunidade escolar e palmeirense, no ciclo de palestras "Matemática e suas possibilidades".

É válido ressaltar que, em paralelo a essa ação e às aulas, os alunos realizaram os cursos: Metodologia Científica, pela plataforma Aprendizagem Interativa em Ciências e Engenharia (APICE); Normas da ABNT aplicadas a Trabalhos Acadêmicos e Leitura e Produção de Textos Acadêmicos, pela Universidade Federal do Recôncavo da Bahia (UFRB), na plataforma AVA Acadêmico. Os referidos cursos os aproximaram da pesquisa científica e escrita acadêmica, questões até então desconhecidas por muito deles.

Em suma, todas as ações da atividade foram registradas no diário de bordo. Os relatórios e slides das palestras foram recolhidos para a correção, bem como para a análise das reflexões de cada grupo acerca do problema investigado.

\section{REFLEXÕES ACERCA DOS RESULTADOS}

Após leitura e correção das pesquisas desenvolvidas pelos estudantes, este material foi submetido à análise e organizado em duas categorias: (i) os projetos de pesquisa e seus resultados e (ii) as reflexões sobre os projetos de pesquisa. As discussões aqui apresentadas forneceram subsídios para que pudéssemos alcançar o objetivo proposto, isto é, desenvolver nos estudantes do Ensino Médio, por meio da metodologia de elaboração de projetos de pesquisa, o letramento estatístico.

\subsection{Os projetos de pesquisa e seus resultados}

Nesta seção são apresentados os projetos de pesquisa desenvolvidos pelos estudantes ao longo das aulas do $2^{\circ}$ trimestre do ano de 2019 , que serviram como base para as discussões acerca do desenvolvimento de conceitos estatístico, bem como o letramento estatístico. No Quadro 1, é possível observar os projetos desenvolvidos e seus respectivos títulos e objetivos.

\begin{tabular}{|c|l|}
\hline Grupo & \multicolumn{1}{c|}{ Descrição } \\
\hline \multirow{3}{*}{ G1 } & $\begin{array}{l}\text { Título: Gravidez na adolescência: uma análise da realidade do Colégio Estadual Profa. Nilde } M^{\mathrm{a}} \text {. } \\
\text { Monteiro Xavier (CEPNMMX) nos últimos cinco anos. }\end{array}$ \\
\cline { 2 - 2 } & $\begin{array}{l}\text { Objetivo: Analisar a incidência de alunas do CEPNMMX que engravidaram nos últimos cinco anos } \\
(2015-2019) .\end{array}$ \\
\hline \multirow{3}{*}{ G2 } & $\begin{array}{l}\text { Título: Satisfação pública acerca dos serviços prestados pela Prefeitura Municipal de Palmeiras - } \\
\text { BA. }\end{array}$ \\
\cline { 2 - 2 } & $\begin{array}{l}\text { Objetivo: Identificar o índice de satisfação da população palmeirense em relação aos serviços } \\
\text { públicos prestados pelo município. }\end{array}$ \\
\hline
\end{tabular}




\begin{tabular}{|c|c|}
\hline & 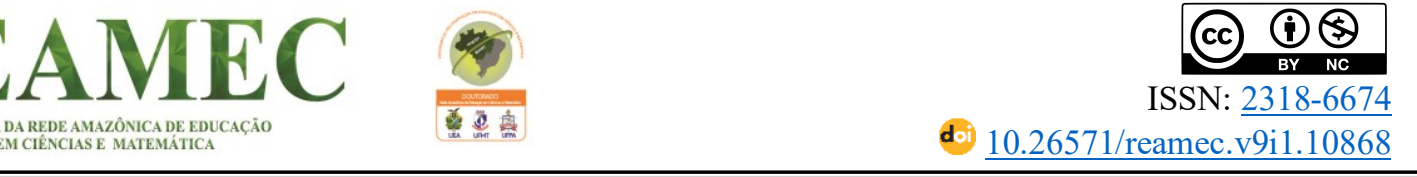 \\
\hline \multirow[b]{2}{*}{ G3 } & Um retrato da diabetes na cidade de Palmeiras - BA. \\
\hline & $\begin{array}{l}\text { Objetivo: Analisar o índice de pessoas diabéticas na cidade, comparando-o com as estatísticas } \\
\text { nacionais. }\end{array}$ \\
\hline \multirow[b]{2}{*}{ G4 } & Palmeiras para além do Vale do Capão: turismo e hospedagem. \\
\hline & $\begin{array}{l}\text { Objetivo: Analisar e identificar os possíveis motivos pela baixa taxa de hospedagem na cidade de } \\
\text { Palmeiras, tendo em vista a crescente taxa de visitantes no município. }\end{array}$ \\
\hline \multirow{2}{*}{ G5 } & $\begin{array}{l}\text { Taxa de analfabetismo no conjunto habitacional Minha Casa, Minha Vida (Casinhas) na cidade de } \\
\text { Palmeiras - BA. }\end{array}$ \\
\hline & $\begin{array}{l}\text { Objetivo: Identificar os níveis de escolaridade das mães e dos pais de família do conjunto } \\
\text { habitacional Minha Casa, Minha Vida da cidade de Palmeiras - BA. }\end{array}$ \\
\hline \multirow[b]{2}{*}{ G6 } & Casos de dengue no Município de Palmeiras entre os anos de 2015 e 2019. \\
\hline & $\begin{array}{l}\text { Objetivo: Compreender o aumento exponencial dos números de casos de dengue em Palmeira - BA } \\
\text { nos últimos cinco anos. }\end{array}$ \\
\hline \multirow[b]{2}{*}{ G7 } & Violência contra a mulher: opiniões da população feminina de Palmeiras - BA. \\
\hline & $\begin{array}{l}\text { Objetivo: Analisar qual a opinião da população feminina de Palmeiras - BA a respeito da violência } \\
\text { contra a mulher. }\end{array}$ \\
\hline \multirow[b]{2}{*}{ G8 } & Alcoolismo entre os jovens da cidade de Palmeiras - BA. \\
\hline & $\begin{array}{l}\text { Objetivo: Identificar quais as concepções da população palmeirense a respeito do consumo de } \\
\text { bebidas alcoólicas por jovens. }\end{array}$ \\
\hline
\end{tabular}

Quadro 1 - Projetos de pesquisa desenvolvidos. Fonte: Dados da pesquisa (2019).

O trabalho com projetos mostrou-se bastante positivo, pois foi possível explorar conceitos estatísticos - inferência, construção de gráficos e tabelas, medidas de tendências centrais, etc. -, bem como aprimorar o conceito de porcentagem, já visto nos anos Finais do Ensino Fundamental. Ainda, favoreceu o desenvolvimento do letramento estatístico, pontuado por Gal (2002), além de habilidades sugeridas pela BNCC - de planejamento e execução de pesquisa amostral (BRASIL, 2018).

É possível inferir que o bom desenvolvimento da atividade se deu graças a uma proposta de trabalho voltada para a realidade dos alunos, ou seja, os problemas investigados por eles fazem referência ao contexto social e local em que estão inseridos. Apesar de temas diversos, o que, inicialmente, mostrou-se um complicador na gestão do trabalho docente, a atividade ocorreu de forma tranquila e os alunos se mostraram autônomos e proativos, pois as investigações propostas por eles se inseriam em suas realidades sociais.

Assim, permitir que os alunos escolhessem o tema a ser investigado foi de fundamental importância para o bom desenvolvimento do trabalho, visto que os discentes se mostraram mais motivados e interessados, participando ativamente de toda a execução da proposta de atividade; este resultado foi evidenciado também em pesquisa realizada por Bianchini, Bisognin e Soares (2015). Desse modo, é possível inferir que, em atividades que trabalham com a pesquisa como ponto de partida, os alunos se mostram abertos a aprender e podem realizar trabalhos satisfatórios, como pode ser observado no Quadro 1 e nas descrições feitas, brevemente, a seguir. 
A pesquisa desenvolvida pelo G1 investigou os casos de gravidez na adolescência nas dependências do CEPNMMX. Para tanto, realizou-se uma busca nos registros da secretaria, dos últimos cinco anos, bem como entrevista com a equipe gestora do colégio. Foi identificado que, mesmo variando, nos últimos cinco anos, a quantidade total de alunas nas dependências da escola, a incidência de casos de gravidez é igual, isto é, cinco alunas grávidas a cada ano. Além disso, aferiu-se que a média de idade dessas alunas é de 16 anos e que $60 \%$ dos casos se concentram no turno vespertino, cujo público é majoritariamente negro e residente em comunidades rurais.

Quanto à pesquisa realizada pelo G2, foi aplicado um questionário com 10 perguntas, a 63 pessoas dos diferentes bairros da sede do município, com idade média de 46 anos, entre os dias 18/05/19 e 28/05/19; optou-se por realizar a pesquisa na sede por ser o maior colégio eleitoral da cidade e, também, devido à falta de transporte para realizar o deslocamento até as comunidades rurais.

Com os resultados apresentados em gráficos e tabelas, o grupo constatou que 39,68\% da população avalia como ruim a atual gestão; 26,98\%, como péssima; 20,6\%, como boa; e 12,74\% não soube responder. Quanto aos serviços prestados (coleta de lixo, segurança, limpeza das vias públicas, conservação das vias, espaços de lazer, escolas, saúde, serviço de abastecimento de água, iluminação pública e esgoto sanitário), estes foram avaliados com média de 4,7\%, muito abaixo do esperado. Além disso, os participantes avaliaram como péssimo o serviço de abastecimento de água e alegaram que já ficaram dias e até semanas sem água; sendo este, juntamente com a educação, esporte, lazer e saúde, os serviços que mais precisam de melhorias.

Já o estudo do G3 investigou os casos de diabetes no município. Assim, elaborou-se um roteiro de entrevista com dez questões, que foi aplicado aos dirigentes da Secretaria Municipal de Saúde (SMS). Com os dados explicitados em gráficos, foi destacado pelo grupo que entre 2016 e 2019 houve um aumento de 36 novos casos da doença, somando-se aos 183 já existentes, alcançando a marca de 219 pessoas diabéticas. O G3 faz uma ressalva a esses números e informa que não foram encontrados dados referentes aos anos de 2017 e 2018, pois, segundo os responsáveis, não havia registros dos anos em questão, como também não se sabe quantas pessoas fazem o acompanhamento corretamente.

O estudo do G4 foi voltado para o turismo e hospedagem, atividades econômicas extremamente fortes na cidade de Palmeiras, bem como na região da Chapada Diamantina Bahia. Para tanto, foram realizadas entrevistas com donos/responsáveis por hotéis, pousadas e 
hostels, entre os dias 06/05/19 e 11/05/19. Além disso, o grupo realizou, via redes sociais, questionamentos a visitantes que passaram pela cidade de Palmeiras. De acordo com os entrevistados, $70 \%$ dos hóspedes que visitam a cidade são brasileiros e estes costumam ficar hospedados, em média, por três dias. Ademais, a procura por hospedagem se concentra nos feriados de Carnaval, Ano Novo e São João, nessa ordem. Constatou-se também que os visitantes têm uma preferência maior em se hospedar em Caetê-Açu (Vale do Capão Distrito de Palmeiras), do que em Palmeiras, dados os serviços que são oferecidos na localidade, que vão de hotéis a pousadas sofisticadas, restaurantes, pizzarias e bares, mesmo a sede do município oferecendo um custo menor em relação à hospedagem e alimentação.

Quanto à pesquisa do G5, tratou-se de um estudo voltado para a taxa de analfabetismo do bairro em que os integrantes do grupo residem. Para tanto, realizaram um questionário com 10 perguntas, que foi aplicado a 50 pessoas residentes nas "Casinhas" (Programa Minha Casa, Minha Vida), seguindo o modelo de pesquisa por domicílio, durante três dias. Os dados coletados foram elencados em dois grupos, mulheres (30) e homens (20), os quais foram organizados e analisados em gráficos e tabelas.

O grupo verificou que 44 dos entrevistados sabem escrever seu nome, mas quando questionados sobre a leitura, apenas 22 falaram que sabiam ler. Outro destaque é que entre os entrevistados, as mulheres apresentaram níveis de escolaridade melhores que os homens, de modo que apenas 20\% deles concluíram o Ensino Médio, diferentemente das mulheres, em que $33,3 \%$ delas afirmaram ter concluído essa etapa escolar. O grupo chama a atenção para os motivos que levaram essas pessoas a abandonarem os estudos e identificou que, enquanto as mulheres apontam como motivos o trabalho (40\%) e os filhos $(36,67 \%), 80 \%$ dos homens afirmaram que desistiram de estudar por conta do trabalho.

A pesquisa do G6 investigou a incidência dos casos de dengue no município. O estudo foi realizado junto à Secretaria Municipal de Saúde, em que o grupo entrevistou a servidora responsável por monitorar os casos de dengue no município. Com os dados dispostos em gráficos e tabelas, o grupo concluiu que houve um crescimento exponencial dos números de casos de dengue, notificados pela Secretaria de Saúde, entre os anos de 2015 a 2019; o número de casos do ano de 2019 é 11 vezes maior (144 casos) que o número de casos do período de 2015 a 2018 (13 casos). Esses números não retratam a realidade, principalmente o período de 2015 a 2018, pois vários foram os relatos de pessoas que afirmaram ter sido infectadas, o que indica que houve subnotificação por parte dos órgãos competentes. Observou-se, ainda, que o ano de 2019 acumula 91,71\% dos casos investigados no período de 
2015 a 2019, reforçando a teoria da subnotificação; outro fator é que estes casos se concentram nos bairros periféricos (Casinhas, Alto da peteca e Mutirão), refletindo as estatísticas nacionais.

O G7 realizou um estudo sobre a violência contra a mulher. Os estudantes elaboraram um questionário, que foi aplicado a 40 mulheres na cidade de Palmeiras. Os resultados apontaram que $87,5 \%$ das entrevistadas se declararam negras (pretas e/ou pardas), permitindo que fosse traçado um perfil das mulheres que residem nos bairros supramencionados. Além disso, $52,5 \%$ dessas mulheres relataram que já sofreram algum tipo de assédio e $20 \%$ diz que já sofreu algum tipo de violência, sendo $22,2 \%$ sexual e $77,8 \%$ psicológica. Os resultados indicam ainda que apenas 7\% das entrevistadas acreditam que as mulheres são tratadas com respeito no Brasil e que $42 \%$ acreditam na eficácia das leis protetivas às mulheres. $\mathrm{O}$ grupo também constatou que, por motivos desconhecidos, essas entrevistadas não relataram sofrer violência física, o que causou estranheza, visto que as estatísticas nacionais apontam essa como a mais recorrente.

A pesquisa desenvolvida pelo G8 investigou o consumo de bebidas alcoólicas entre os jovens palmeirenses. O grupo realizou uma pesquisa com 50 pais e responsáveis e constatou que $98 \%$ dos entrevistados analisam a situação com preocupação, de modo que a consideram como um problema social e familiar, pois esse consumo interfere no amadurecimento, na educação, na vida social, profissional e familiar desses jovens. Assim sendo, $64 \%$ dos entrevistados dizem que não se sentem confortáveis que seus filhos andem na companhia de jovens que consomem bebidas alcoólicas; contudo, $44 \%$ dos entrevistados falaram que nunca refletiram sobre o consumo de bebidas alcoólicas por pais/mães na frente dos filhos.

Os dados apontam também que $32 \%$ acredita que os pais/mães não têm poder de influenciar seus filhos a consumirem bebidas alcoólicas, o que pode ser refutado quando observamos que o seio familiar é primordial na construção de nossos costumes e valores.

Diante dos resultados dos projetos é possível perceber a importância do trabalho com a Estatística no Ensino Básico, a partir da realidade dos estudantes, cujo ponto de partida é embasado em questões sociais reais e que são vivenciadas por eles em seu cotidiano. Isto porque conceitos estatísticos - gráficos, tabelas, índices, medidas de tendências centrais e dispersão - ganham novos significados, diferentes se fossem abordados no contexto da aula expositiva (LOPES, 2008). Assim, propor a discussão de temas como os apresentados no Quadro 1, além de possibilitar a construção de conceitos estatísticos, favorece o desenvolvimento da reflexão e criticidade (BIANCHINI; BISOGNIN; SOARES, 2015). 


\subsection{As reflexões sobre os projetos de pesquisa}

Nesta seção, serão apresentadas as reflexões dos estudantes, expressas nas discussões durante as aulas, no relatório de pesquisa e na socialização dos resultados apresentados na palestra "Matemática e suas possibilidades". As falas e posicionamentos dos estudantes, ao longo do desenvolvimento da proposta de atividade, apontam para o crescimento pessoal, desenvolvimento da criticidade e a necessidade de mudança do contexto no qual eles estão inseridos.

Durante as ações da atividade, ao longo da produção e coleta dos dados, em que estávamos trabalhando conceitos estatísticos a partir da investigação dessas informações, como também durante a palestra, alguns grupos fizeram colocações que apontam as contribuições da atividade para o crescimento pessoal e coletivo, conforme falas a seguir:

Gostariamos de informar a todos os presentes que ao final deste trabalho conseguimos entender as consequências que uma gravidez na adolescência pode trazer não apenas para as meninas, mas para os meninos também, pois elas sozinhas não podem gerar um bebê. É preciso que a gente se cuide. Criar uma criança requer muita responsabilidade. Na real, galera, gravidez na adolescência não é legal! (Reflexões do G1 durante a palestra, 2019).

Esse trabalho tá numa exigência que só, é tanta reflexão que não parece ser de Matemática, parece que estamos nas aulas de Sociologia. Não imaginava que a Matemática, a Estatística, fossem tão importantes para compreender os problemas e dificuldades da minha cidade (Posicionamento do G2 durante as aulas, 2019).

As falas dos estudantes do G1 e G2 possibilitam inferir que as ações da atividade proposta transcenderam o contexto da Matemática e da sala de aula, passando a auxiliar os alunos na tomada de decisão (LOPES, 2008). Por exemplo, quando os integrantes do G1 pontuam que gravidez na adolescência não é legal, sugerem que, com a gravidez, vem um possível abandono dos estudos, os amigos se afastam e há uma mudança no estilo de vida; ou quando o G2 cita a importância da Estatística na compreensão dos problemas e difículdades da cidade.

Observa-se ainda, na fala do G2, a relação que os estudantes fazem das discussões do trabalho com a disciplina Sociologia. Parece haver um consenso entre os alunos que, em Matemática, não há reflexão e que não se pode discutir questões sociais, visto que tais discussões são reservadas exclusivamente para as disciplinas da área de Humanas. De fato, durante muito tempo se pensou assim, mas o papel da Escola e da Matemática na formação dos alunos mudou com o passar dos anos, por isso a importância de realizar atividades em que 
a pesquisa é o ponto de partida, pois as ações que são desenvolvidas ao longo da atividade tornam as aulas mais instigantes e reflexivas (BIANCHINI; BISOGNIN; SOARES, 2015).

Diante da possibilidade de poder refletir dentro do contexto da Matemática, várias foram as críticas suscitadas pelos estudantes na escrita do relatório e nas palestras, convergindo com as ideias de Cazorla et al. (2017) a respeito da formação crítica frente às questões de cunho social, político, cultural e científico. Nas falas que seguem, os estudantes do G5 e G7 nos convidam a refletir criticamente acerca do analfabetismo e da violência contra a mulher, ambos, relacionados à população negra.

O analfabetismo no Brasil tem cor e classe, e sabemos muito bem qual é. Dados do IBGE apontam que entre pretos e pardos os índices de analfabetismos são muito maiores, bem como entre os pobres. Essa realidade não foi diferente em nosso estudo. $92 \%$ das pessoas que entrevistamos se identificam enquanto preto ou pardo, sendo que destes, apenas 47,8\% afirmaram saber ler, escrever e realizar operações matemáticas básicas. A população negra (pretos/pardos) ainda está à margem da sociedade quando o assunto é educação pública de qualidade (Reflexões do G5 durante a palestra, 2019).

Em quanto mais perfis de minorias você se identifica, mais propenso você está à violência. Pois é, pessoal, se você é mulher, você tem chances de ser violentada; se você é mulher e negra, essas chances mais que dobram. Das mulheres que entrevistamos, as que relataram sofrer algum tipo de violência se identificam como pretas ou pardas, convergindo com dados nacionais. Estas pontuaram ainda que não sabem se o que aconteceu pode ou não ser considerado violência, e isso parece ser comum; visto que, historicamente, a naturalização e banalização são elementos comuns em nossa sociedade machista, desde os tempos de colonização (Informações contidas no relatório do G7, 2019).

Observa-se que os estudantes refletem criticamente acerca dos problemas abordados e vão além, fazendo o cruzamento dos dados de seus estudos com as estatísticas nacionais, convergindo com o que Lopes (2008) chama de exercício da cidadania, ou seja, a capacidade de atuação reflexiva e crítica de um indivíduo em seu grupo social. É válido ressaltar que todos os integrantes do G5 se declararam enquanto negros e residem no bairro em que a pesquisa foi realizada, já o G7 é formado por três alunas e um estudante não-binário ${ }^{4}$.

Assim, quando ambos os grupos pautam uma discussão no âmbito de raça e de gênero, questões importantes do ponto de vista da formação integral do aluno, proposta pela BNCC (BRASIL, 2018), eles não só refletem criticamente acerca dos problemas sociais abordados, mas também do seu lugar de fala enquanto homem negro, mulher negra e pessoa não-binária, que foram pontos de pauta em muitas discussões, de modo que agora falam por si sós.

Ainda com relação às discussões de gênero, o relatório do G5 permite identificar como a relação patriarcal contribui para o crescimento da taxa de analfabetismo entre as mulheres,

\footnotetext{
${ }_{-}^{4}$ Pessoa cuja identidade de gênero não é inteiramente masculina ou feminina.
} 
mesmo estas apresentando melhores resultados em relação aos homens, conforme trecho a seguir:

Chega ser estranho analisarmos essas informações e perceber que nenhum homem, dos 20 que realizamos a pesquisa, desistiu dos estudos por conta dos filhos. Situação diferente do grupo das mulheres, em que 36,6\%, das 30 entrevistadas afirmaram que deixaram de estudar porque precisavam cuidar dos filhos. Essas informações apenas confirmam o quão ainda é forte a relação patriarcal na maioria das famílias, em que para as mulheres cabe o papel de cuidar dos filhos e da casa, enquanto ao homem a busca por proventos para sustentar a família (Informações contidas no relatório do G5, 2019).

A discussão levantada pelos integrantes do G5 é uma questão social que ainda afeta muitos lares; mas algo, até então, não percebido por eles. Ao se arriscarem numa discussão nesse viés, os alunos não só construíram conceitos estatísticos, mas fizeram descobertas, como sugerido por Piaget (1976), isto é, que o machismo contribui para a taxa de analfabetismo entre as mulheres, como também reduzir o papel da mulher a cuidar dos filhos e da casa é retrógrado, sexista e machista.

Ainda com relação ao exercício da cidadania, os G3 e G7, na tentativa de mudar o seu meio, fazem críticas ao contexto local, à população e apontam problemas que precisam da atenção das autoridades locais e dos munícipes, como pode ser observado a seguir:

\footnotetext{
Houve um aumento significativo dos casos de diabetes em nossa cidade e, com isso, é necessário que ações sejam realizadas com urgência. A primeira diz respeito à necessidade de se contratar profissionais qualificados que saibam operar o atual sistema de regulação dos casos de diabetes; a segunda seria uma melhoria do próprio sistema. De acordo com as informações que recolhemos houve uma perda significativa de informações, completamente necessárias para nosso trabalho, quanto para a realização dos acompanhamentos das pessoas que são diabéticas. Aqui cabe um questionamento: como minimizar os efeitos de uma doença em que o portador é desconhecido? (Reflexões do G3 durante a palestra, 2019).
}

Detentora do título de coração da chapada diamantina, Palmeiras é uma das cidades que apresenta menor número de procura por hospedagem, perdendo inclusive para seu distrito Caeté-Açu (Vale do Capão), $20 \mathrm{~km}$ distante da sede. Presumimos que isso se deva, principalmente, pela desvalorização da própria população, pela falta de infraestrutura, desde restaurantes e bares, bem como a falta de campanhas publicitárias que divulguem as vantagens de ficar na cidade. (Reflexões do G7 durante a palestra, 2019).

As falas do G3 e G7 apontam as contribuições que o trabalho com a Estatística, na Educação Básica, pode proporcionar para a formação dos estudantes, como proposto por Cazorla et al. (2017). Além disso, definem exatamente o que Gal (2002) classifica como letramento estatístico, e também o desenvolvimento do exercício para a cidadania sugerido por Lopes (2008). 
Na fala do G3, observa-se uma crítica ao aumento dos casos de diabetes na cidade; contudo, percebe-se que não é uma crítica pela crítica, pois os estudantes fazem uma leitura para além dos dados quando destacam que é difícil minimizar os efeitos da doença quando o portador é desconhecido, e passam a refletir sobre a situação, apontando sugestões de como esses números podem ser controlados, indo ao encontro do que é proposto pelo $\mathrm{PCN}+$ (BRASIL, 2002) e por Bianchini, Bisognin e Soares (2015). Na mesma direção, as reflexões levantadas pelo G7 não só fazem uma crítica à equipe de marketing da cidade, como mostram o quão importante é a construção da noção de pertencimento e identidade, como pontuado por Carvalho (2012).

O G7, ainda com relação à necessidade de se construir a noção de pertencimento e territorialidade, reflete criticamente sobre seu papel na sociedade, como pode ser observado no trecho que segue:

\begin{abstract}
Nós, palmeirenses, não valorizamos a nossa cidade. Não construímos a ideia de pertencimento e identidade chapadense. As pessoas que nos visitam ficam apaixonadas, diferentemente de nós. Portanto, é necessário que haja um trabalho aqui no colégio, nas escolas municipais, acerca da educação patrimonial. Precisamos nos tornar pessoas melhores, mais conscientes de nossas responsabilidades ambientais, de conservação do patrimônio material e imaterial de nossa cidade (Reflexões do G7 durante a palestra, 2019).
\end{abstract}

A fala do G7 confirma as ideias postas por Carvalho (2012), ao pontuar que o ambiente escolar é fundamental para a construção da identidade de crianças e adolescentes. Quando os estudantes do G7 reconhecem a Escola enquanto local privilegiado para a mudança social, da construção de suas responsabilidades ambientais e de conservação, demonstram a importância do trabalho com a Estatística no Ensino Básico e como esse trabalho auxilia os alunos na tomada de decisão (LOPES, 2008; CAZORLA et al., 2017; CONCEIÇÃO et al., 2019), neste caso: a necessidade de se tornar pessoas melhores e conscientes de suas responsabilidades (exercício pleno da cidadania).

Reforçando o que Lopes (2008) e Carvalho (2012) enfatizam a respeito do exercício da cidadania e da construção da noção de pertencimento e identidade, o G6 e o G8 durante a palestra fizeram sugestões de ações que visam à mudança do município, a fim de se construir uma cidade melhor, mais organizada e consciente, conforme os trechos a seguir:

Apesar de ser um estudo pequeno, nossos resultados refletem as estatísticas nacionais e de estudos maiores, isto é, que bairros periféricos, sem saneamento básico adequado, estão propícios a apresentar altos índices de casos de dengue. Em nosso município mesmo, os casos de dengue se concentram nas zonas periféricas Casinhas e Mutirão. Portanto, é necessário que nós, juntamente com nossos familiares e os agentes de endemias, tomemos as medidas necessárias para eliminar 
os focos que contribuam para a proliferação do mosquito, tais como casca de ovos, garrafas, latas, pneus e outros (Reflexões do G6 durante a palestra, 2019).

De acordo com as informações coletadas, é necessário que os órgãos competentes no município busquem por alternativas para diminuir os índices de alcoolismo entre os jovens; uma possibilidade seria exercer um controle maior sobre a venda de bebidas para menores, não há fiscalização alguma quanto a isso, nós sabemos disso! Assim, o alcoolismo, não só em nossa cidade, mas em todo território nacional, deveria ser entendido como um problema de saúde pública e tratado com políticas públicas eficazes (Informações contidas no relatório do G8, 2019).

Nota-se que ambas as falas têm algo em comum: cabe ao poder público municipal o primeiro passo para a mudança. Desse modo, as reflexões críticas levantadas pelos G6 e G8 convergem com o que se espera do trabalho com a Estatística no Ensino Básico, o que é pontuado por diversos autores (LOPES, 2008; BIANCHINI; BISOGNIN; SOARES, 2015; CAZORLA et al., 2017), pelos PCN+ (BRASIL, 2002) e pela BNCC (BRASIL, 2018). A partir do momento em que jovens, por meio de um trabalho escolar, conscientizam-se acerca de seu papel na sociedade, demonstra-se o quão importante é o trabalho com a Estatística na Educação Básica.

Diante do exposto, as reflexões e críticas suscitadas pelos grupos miram na mudança do contexto local, sendo essa uma característica da proposta de trabalho que tem como pano de fundo o ensino de Estatística por meio de projetos. Isto faz com que os estudantes percebam o seu lugar, os seus problemas e possibilidades de superação, além de desenvolverem competências e habilidades (BRASIL, 2018). Destarte, a partir do emprego de conceitos estatísticos adequados e uma reflexão crítica acerca dos dados, os estudantes poderão ultrapassar a simples leitura de informações reunidas por eles ou terceiros e passarão a refletir sobre os seus significados e impactos no meio social, tornando-se pessoas conscientes e capazes de tomar decisões. E mais, desenvolvem-se, neste processo, o letramento estatístico, a criticidade e a noção de pertencimento e identidade.

\section{CONSIDERAÇÕES FINAIS}

Diversos estudos têm apontado que o ensino de Estatística, desde os primeiros anos escolares, contribui para o desenvolvimento do letramento estatístico, da criticidade e reflexão dos alunos para o exercício pleno da cidadania. Dito isso, é possível concluir que o objetivo proposto, a saber: desenvolver nos estudantes do Ensino Médio, por meio de projetos de pesquisa, o letramento estatístico e a criticidade, foi alcançado. 
Durante as aulas, de posse dos questionários, enquanto discutíamos os conceitos de gráficos, tabelas e medidas de tendência central, os alunos começaram a perceber a importância de tais conceitos para a interpretação daqueles dados, como também passaram a compreender o conceito em si. Em especial, quando o G2 e o G7, que pesquisaram sobre satisfação política e violência contra a mulher, respectivamente, concluíram que seus dados ficaram mais claros quando apresentados em gráficos de barra; enquanto os dados do G3 e G6, diabetes e dengue, ficariam melhores em gráficos de linhas.

Além disso, os alunos do G1, a partir de seus dados, bem como os outros estudantes da turma, puderam compreender o conceito de moda ao observar os casos de gravidez entre as alunas do colégio. Assim, ao final da atividade, os alunos passaram a perceber a Estatística por outra lente, diferente da apresentada nos livros didáticos. Isto porque, a partir da análise, comparação e interpretação de dados dispostos em tabelas e gráficos, bem como a capacidade que desenvolveram para organizar os dados produzidos e coletados, eles perceberam que podem emitir opiniões e refletir sobre esses dados, a fim de tomar decisões e mudar seu contexto social e local.

Desse modo, os resultados expressam as contribuições e possibilidades da inclusão da elaboração de projetos na metodologia de ensino, tendo em vista a construção de conceitos estatísticos no Ensino Médio. É válido salientar que a proposta em questão abre possibilidades para um trabalho interdisciplinar com a Sociologia e área de linguagem, no intuito de investigar, de maneiras mais profundas, as questões sociais e relações de poder, bem como o desenvolvimento de habilidades e competências referentes à escrita de textos científicos.

Portanto, o ensino de Estatística via projetos de pesquisa, tendo como ponto de partida o contexto social e local dos alunos, mostrou-se de fundamental importância para o envolvimento dos estudantes durante todas as ações da atividade. Assim, conclui-se que o trabalho com esses projetos motiva os estudantes a participarem ativamente do processo de ensino, bem como favorece a aprendizagem de conceitos estatísticos, além de auxiliar no desenvolvimento da reflexão e da criticidade, levando-os a questionar os papéis que desempenham na sociedade, principalmente no que diz respeito ao exercício da cidadania.

\section{REFERÊNCIAS}

BIANCHINI, D. F.; BISOGNIN, C.; SOARES, D. S. Uma proposta didática para o ensino de estatística: o uso do Excel para representação gráfica. RENOTE: Revista Novas Tecnologias na Educação, v. 13, n. 2, dez. 2015. Disponível em:

https://seer.ufrgs.br/renote/article/view/61431. Acesso em: 20 maio 2020. 
BRASIL. Ministério da Educação e Cultura. PCN+: Orientações Educacionais Complementares aos Parâmetros Curriculares Nacionais para o Ensino Médio: ciências da natureza, matemática e suas tecnologias. Brasília: Ministério da Educação e Cultura, 2002. Disponível em: http://portal.mec.gov.br/seb/arquivos/pdf/CienciasNatureza.pdf. Acesso em: 26 fev. 2020.

BRASIL. Ministério da Educação. Base Nacional Curricular Comum. Brasília: Ministério da Educação, 2018. Disponível em: http://portal.mec.gov.br/conselho-nacional-deeducacao/base-nacional-comum-curricular-bncc-etapa-ensino-medio. Acesso em: 26 fev. 2020.

BURAK, D. Critérios norteadores para a adoção da modelagem matemática no ensino secundário e fundamental. Revista Zetetiké, Campinas, v. 2, n. 1, p. 47-60, 1994. Disponível em: https://periodicos.sbu.unicamp.br/ojs/index.php/zetetike/article/view/8646925. Acesso em: 26 fev. 2020.

CARVALHO, M. A construção das identidades no espaço escolar. Revista Reflexão e Ação, v. 20, p. 209-227, 2012. Disponível em:

https://online.unisc.br/seer/index.php/reflex/article/viewFile/2161/2521. Acesso em: 26 fev. 2020.

CAZORLA, I.; MAGINA, S.; GITIRANA, V.. GUIMARÃES, G. (Org.). Estatística para os Anos Iniciais do Ensino Fundamental. Brasília: Sociedade Brasileira de Educação Matemática - SBEM, 2018. (Coleção SBEM). Disponível em: http://www.sbem.com.br/files/ebook_sbem.pdf. Acesso em: 15 maio 2020.

FREITAS, K. S. Pedagogia de projetos. GERIR, Salvador, v. 9, n. 29, p. 17-37, 2003. Disponível em: http://www.liderisp.ufba.br/modulos/pedagproj.pdf. Acesso em: 26 fev. 2020.

GAL, I. Adults Statical Literacy: meanings, componentes, responsibilities. International Statistical Review, v. 70, n .1, p. 1-25, 2002.

LOPES, C. E. O Ensino da Estatística e da Probabilidade na Educação Básica e a Formação dos Professores. Caderno Cedes, v. 28, n. 74, jan./abr. 2008. Disponível em: http://www.scielo.br/pdf/ccedes/v28n74/v28n74a05.pdf. Acesso em: 20 maio 2020.

BRASIL. Ministério da Educação. Média em Matemática está entre as menores do PISA. Brasil: Ministério da Educação, Disponível em: http://portal.mec.gov.br/component/content/article?id=42771. Acesso em: 26 fev. 2020.

MOURA, D. G.; BARBOSA, E. F. Trabalhando com projetos: planejamento e gestão de projetos educacionais. Edição Digital. Petrópolis, RJ: Editora Vozes, 2017. Disponível em: https://books.google.com.br/books/about/Trabalhando com projetos.html?id=W9Q5DwAAQ BAJ\&printsec $=$ frontcover\&source $=\mathrm{kp}$ read button\&redir esc $=\mathrm{y} \# \mathrm{v}=$ twopage\& $\mathrm{q} \& \mathrm{f}=$ false . Acesso em: 26 fev. 2020.

OLIVEIRA, C. L. Significado e contribuições da afetividade, no contexto da Metodologia de Projetos, na Educação Básica. 2006. 20 f. Dissertação (Mestrado) - Centro Federal de Educação Tecnológica de Minas Gerais, Pós-Graduação em Educação Tecnológica, Belo 


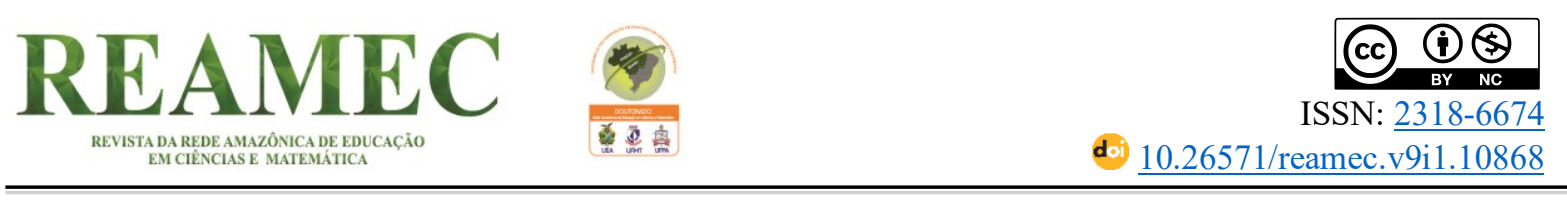

Horizonte, 2006. Disponível em:

http://www.tecnologiadeprojetos.com.br/banco_objetos/\%7B28A0E37E-294A-4107-906C-

914B445E1A40\%7D pedagogia-metodologia.pdf. Acesso em: 26 fev. 2020.

PIAGET, J. A Formação do Símbolo na Criança: imitação, jogo e sonho, imagem e representação. 3. ed. Rio de Janeiro: Zahar, 1978.

TODOS Pela Educação. Anuário Brasileiro da Educação Básica 2019. Disponível em: https://www.todospelaeducacao.org.br/_uploads/_posts/302.pdf. Acesso em: 26 fev. 2020.

\section{NOTAS}

\section{AGRADECIMENTOS}

Aos alunos e alunas do $3^{\circ}$ ano/2019 do Ensino Médio do Colégio Estadual Professora Nilde Maria Monteiro Xavier.

\section{FINANCIAMENTO}

Não se aplica.

\section{CONTRIBUIÇÕES DE AUTORIA}

Resumo/Abstract/Resumen: Jadson de Souza Conceição.

Introdução: Jadson de Souza Conceição.

Referencial teórico: Jadson de Souza Conceição.

Análise de dados: Jadson de Souza Conceição.

Discussão dos resultados: Jadson de Souza Conceição.

Conclusão e considerações finais: Jadson de Souza Conceição.

Referências: Jadson de Souza Conceição.

Revisão do manuscrito: Jadson de Souza Conceição.

Aprovação da versão final publicada: Jadson de Souza Conceição.

\section{CONFLITOS DE INTERESSE}

$\mathrm{O}$ autor declara não haver nenhum conflito de interesse de ordem pessoal, comercial, acadêmico, político e financeiro referente a este manuscrito.

\section{DISPONILIDADE DE DADOS DE PESQUISA}

$\mathrm{O}$ autor declara que disponibilizara os dados referentes a esta pesquisa a quem solicitar, por meio das informações de contato supracitadas. Estes, advém dos instrumentos de produção de dados utilizados nesta pesquisa, a saber: relatório dos estudantes e slides das apresentações.

\section{CONSENTIMENTO DE USO DE IMAGEM}

Não se aplica.

\section{COMO CITAR - ABNT}

CONCEIÇÃO, Jadson de Souza. Da elaboração de projetos à construção de conceitos estatísticos: uma experiência com alunos do Ensino Médio. REAMEC - Rede Amazônica de Educação em Ciências e Matemática. Cuiabá, v. 9, n.1, e21014, janeiro-abril, 2021. DOI: 10.26571/reamec.v9i1.10868.

COMO CITAR - APA

CONCEIÇÃO, J. S. (2021). Da elaboração de projetos à construção de conceitos estatísticos: uma experiência com alunos do Ensino Médio. REAMEC - Rede Amazônica de Educação em Ciências e Matemática, 9(1), e21014. DOI: $10.26571 /$ reamec.v9i1.10868.

\section{LICENÇA DE USO}

Licenciado sob a Licença Creative Commons Attribution-NonCommercial 4.0 International (CC BY-NC 4.0). Esta licença permite compartilhar, copiar, redistribuir o manuscrito em qualquer meio ou formato. Além disso, 
permite adaptar, remixar, transformar e construir sobre o material, desde que seja atribuído o devido crédito de autoria e publicação inicial neste periódico.

\section{DIREITOS AUTORAIS}

Os direitos autorais são mantidos pelos autores, os quais concedem à Revista REAMEC - Rede Amazônica de Educação em Ciências e Matemática - os direitos exclusivos de primeira publicação. Os autores não serão remunerados pela publicação de trabalhos neste periódico. Os autores têm autorização para assumir contratos adicionais separadamente, para distribuição não exclusiva da versão do trabalho publicada neste periódico (ex.: publicar em repositório institucional, em site pessoal, publicar uma tradução, ou como capítulo de livro), com reconhecimento de autoria e publicação inicial neste periódico. Os editores da Revista têm o direito de proceder a ajustes textuais e de adequação às normas da publicação.

\section{PUBLISHER}

Universidade Federal de Mato Grosso. Programa de Pós-graduação em Educação em Ciências e Matemática (PPGECEM) da Rede Amazônica de Educação em Ciências e Matemática (REAMEC). Publicação no Portal de Periódicos UFMT. As ideias expressadas neste artigo são de responsabilidade de seus autores, não representando, necessariamente, a opinião dos editores ou da referida universidade.

\section{EDITOR}

Dailson Evangelista Costa

\section{HISTÓRICO}

Submetido: 24 de julho de 2020.

Aprovado: 16 de novembro de 2020.

Publicado: 26 de janeiro de 2021. 